\title{
Notch signaling activation contributes to cardioprotection provided by ischemic preconditioning and postconditioning
}

Xue-liang Zhou, Li Wan, Qi-rong Xu, Yong Zhao and Ji-chun Liu*

\begin{abstract}
Background: Notch signaling is known to be activated following myocardial ischemia, but its role in cardioprotection provided by ischemic preconditioning (IPC) and ischemic postconditioning (IPost) remains unclear.

Methods: Lentiviral vectors were constructed to overexpress or knockdown N1ICD in H9c2 cardiomyocyte and rat heart exposed to ischemia reperfusion injury (IRI), IPC or IPost.

Results: Notch1 signaling was activated during myocardial IPC and IPost, and could enhance cell viability and inhibit apoptosis. Furthermore, activated Notch1 signaling stabilized mitochondrial membrane potential and reduced reactive oxygen species induced by IRI. The cardioprotection provided by activated Notch1 signaling resembled that of IPC and IPost, which was related to Stat3 activation and regulation of apoptosis related proteins. Furthermore, in langendorff heart perfusion model, activated Notch1 signaling restored cardiac function, decreased lactate dehydrogenase release and limited infarct size after myocardial ischemia. Conclusions: Notch1 signaling is activated and mediates cardioprotection provided by IPC and Ipost. Notch1 signaling may represent a potential new pharmacologic mimic for cardioprotection of ischemic heart disease.
\end{abstract}

Keywords: Notch signaling, Mitochondrial permeability transition pore, Stat3, Ischemic preconditioning, Ischemic postconditioning

\section{Introduction}

It is well known that immediate restoration of cardiac blood flow after prolonged ischemia would contradictorily result in ischemia reperfusion injury (IRI), which would accelerate the deterioration of cardiac function [1]. Ischemia preconditioning (IPC) has shown beneficial effects such as limiting infarct size and reducing lethal arrhythmia after IRI in many species including human being $[2,3]$. On the other hand, ischemia postconditioning (IPost) indicates brief episodes of nonlethal ischemia/reperfusion applied at the onset of reperfusion [4]. Accumulating evidence indicates that IPC and IPost activate various survival signaling pathways to provide cardioprotection [5,6]. Therefore, developing pharmacologic mimics such as endogenous autacoids to provide myocardial protection have important

\footnotetext{
* Correspondence: liujichun999@163.com

Department of Cardiac Surgery, The First Affiliated Hospital, Nanchang University, Nanchang 330006, China
}

\section{Biomed Central}

(c) 2013 Zhou et al.; licensee BioMed Central Ltd. This is an open access article distributed under the terms of the Creative Commons Attribution License (http://creativecommons.org/licenses/by/2.0), which permits unrestricted use, distribution, and reproduction in any medium, provided the original work is properly cited. clinical significance for the treatment of ischemic heart disease (IHD).

Notch signaling is an evolutionary conserved signaling pathway which plays a crucial role in cell fate decision, cell differentiation, proliferation, and apoptosis [7]. There are four receptors (Notch1-4) and five ligands (Jagged1-2 and Delta like 1, -3,-4) in mammals, the hairy and enhancer of split (Hes) and hes-related (Hey) families of transcriptional repressors have been identified as Notch classical target genes [8]. Notch signaling has been implicated in heart disease. Notch1 and Jagged1 levels were lower in adult heart, but N1ICD, Jagged1 and Delta4 were accumulated in the border zone of the infarct region at 4 days after ischemia [9]. Quantitative RT-PCR analysis revealed that the expression of Notch1-4, Jagged1 and Hes1 were increased within the first week following myocardial infarct [10]. Notch signaling was activated in cardiomyocytes 
during post-infarction remodeling, and the expression of Notch1, Jagged1 and Hes1 were upregulated in dilated or hypertrophic hearts [11]. In addition, Notch signaling can stimulate immature cardiomyocyte proliferation and promote quiescent cardiomyocytes to reenter the cell cycle $[12,13]$. However, whether activated Notch signaling following myocardial ischemia plays cardioprotective effects during IPC and IPost remains unclear.

Therefore, in this study we investigated the role of Notch1 signaling in cardioprotection provided by IPC and IPost, using both cardiomyocyte and rat heart model. Our results showed that the inhibition of Notch1 signaling via the knockdown of N1ICD abrogated the cardioprotection provided by IPC and IPost.

\section{Materials and methods Reagents and antibodies}

Dulbecco's modified Eagle's medium (DMEM) and trypsin were from Gibco BRL (USA). Fetal bovine serum (FBS) was from NQBB International Biological Corporation (Australia). Cell counting kit-8 (CCK-8) and Reactive oxygen species assay kits were from Beyotime institute of biotechnology (China). Annexin V-FITC apoptosis detection kit was obtained from KeyGEN Biotech(China). Mitochondria staining kit (JC-1) was purchased from MultiSciences Biotech (USA). Mitochondria isolation kit was purchased from Applygen Technologies (China). LDH kits were purchased from Nanjing jiancheng bioengineering institute, 2,3,5-triphenyltetrazolium chloride (TTC) was from SolarbioTechnologies (China). Enhanced chemiluminescence kit was purchased from Thermo Scientific (USA).

Notch1 and Hes1 antibodies were purchased from Abcam (USA), Flag, Bcl-xL and Bax antibodies were purchased from Cell Signaling Technology (USA), Stat3, p-Stat3 and $\beta$-Actin antibodies were purchased from Anbo Biotechnology Company (USA).

\section{Cell culture}

Rat cardiac H9c2 cells (ATCC Rockville, USA) were cultured in DMEM supplemented with $10 \% \mathrm{FBS}$ at $37^{\circ} \mathrm{C}$ in a humidified incubator with $5 \% \mathrm{CO}_{2}$. The cells were fed every 3 days and subcultured once reaching $90 \%$ confluence. Cells were plated at an appropriate density according to each experimental design.

\section{Virus vector construction and infection}

Rat N1ICD cDNA (Notch1:5456-7819) was generated by PCR using forward primer: 5' -GAGGATCCCCGGGTAC CGGTCGCCACCATGGTGCTGCTGTCCCGCAAG-3' and reverse primer: 5'-TCATCCTTGTAGTCGCTAGCC TTAAATGCCTCTGGAATG-3'. The amplified fragment was subcloned into pGC-FU-EGFP-3Flag to get pGC-FUN1ICD-3Flag vector. Rat N1ICD-shRNAs were designed according to Ambion with the following sequences:
GCACAGTGCTGAGTACCAA (N1ICD-shRNA-1), GCC TCTCCACCAATACCTT (N1ICD-shRNA-2), CCCACAT TCCAGAGGCATT (N1ICD-shRNA-3), TCTGGATGCC CGAATGCAT (N1ICD-shRNA-4) with CTCGAG as the loop sequence. The oligonucleotide-annealed products were subcloned into pGVC112 to get pGVC112-N1ICDshRNA vectors. An irrelevant TTCTCCGAACGTGTCA CGT was used as negative control.

To generate lentiviral vectors, either $20 \mu \mathrm{g}$ pGC-FUN1ICD-3Flag or pGVC112-N1ICD-shRNA was transfected along with $15 \mu \mathrm{g}$ pHelper 1.0 and $10 \mu \mathrm{g}$ pHelper 2.0 into $293 \mathrm{~T}$ cells in $10 \mathrm{~cm}$ plate at $80 \%$ confluence for $8 \mathrm{~h}$. The medium was replaced with fully supplemented DMEM and the supernatants were harvested after $72 \mathrm{~h}$ for virus titration, which were then stored at $-80^{\circ} \mathrm{C}$.

To infect H9c2 cells, multiplicity infection (MOI) of 20 lentiviral particles with $5 \mu \mathrm{g} / \mathrm{ml}$ polybrene were added into the medium, $24 \mathrm{~h}$ later the medium was changed and $\mathrm{H} 9 \mathrm{c} 2$ cells were cultured for an additional $72 \mathrm{~h}$.

To infect Sprague-Dawley rat, $100 \mu \mathrm{l}$ pseudo viral particles $\left(1 \times 10^{8} / \mathrm{ml}\right)$ were injected into the tail vein, 4 weeks after infection, Sprague-Dawley rats were collected for analysis.

In vitro protocols of hypoxia/reoxygenation (H/R), IPC, IPost For H/R, H9c2 cells were cultured in hypoxic solution in a hypoxic incubator $\left(95 \% \mathrm{~N}_{2}-5 \% \mathrm{CO}_{2}\right)$ for $3 \mathrm{~h}$, subsequently hypoxic solution was replaced with reoxygenation solution, and the cells were cultured in a high oxygen incubator $\left(95 \% \mathrm{O}_{2}-5 \% \mathrm{CO}_{2}\right)$ for $3 \mathrm{~h}$.

For IPC, H9c2 cells were cultured in hypoxic solution in a hypoxic incubator $\left(95 \% \mathrm{~N}_{2}-5 \% \mathrm{CO}_{2}\right)$ for $10 \mathrm{~min}$, subsequently the hypoxic solution was replaced with reoxygenation solution, and the cells were cultured in a high oxygen incubator $\left(95 \% \mathrm{O}_{2}-5 \% \mathrm{CO}_{2}\right)$ for $10 \mathrm{~min}$. The hypoxia-reoxygenation cycle was repeated 3 times and followed by $\mathrm{H} / \mathrm{R}$ treatment.

For IPost, at the end of the $3 \mathrm{~h}$ hypoxia, the hypoxic solution was replaced with reoxygenation solution and H9c2 cells were cultured in a high oxygen incubator for $10 \mathrm{~min}$. Next the medium was changed to hypoxic solution and the cells were cultured in a hypoxic incubator for another $10 \mathrm{~min}$. The reoxygenation-hypoxia cycle was repeated 3 times and followed by continuous culture in reoxygenation solution in a high oxygen incubator for $3 \mathrm{~h}$.

\section{Cell viability assay}

H9c2 cells were seeded into a 96-well plate at 10,000 cells/well and cultured in $100 \mu \mathrm{L}$ DMEM supplemented with $10 \%$ FBS for $24 \mathrm{~h}$, then treated as indicated. Finally, the cell viability was detected using CCK-8 Kit (Dojindo, Japan) according to the manufacturer's instructions. The absorbance was measured at $450 \mathrm{~nm}$ using a Microplate 
reader (Thermo, USA). The percentage of viable cells was calculated with the control cells set as $100 \%$.

\section{Apoptosis assay}

H9c2 cells were harvested and $4 \times 10^{5}$ cells were resuspended in $500 \mu \mathrm{l}$ binding buffer, then incubated with $5 \mu \mathrm{l}$ Annexin V-FITC and $5 \mu \mathrm{l}$ propidium iodide (PI) at room temperature in dark for $15 \mathrm{~min}$. The samples were analyzed by flow cytometry with a BD FACSCalibur. Apoptosis ratio was defined as the ratio between Annexin $\mathrm{V}$ positive/PI negative cells and the total living cells.

\section{Detection of intracellular reactive oxygen species (ROS)}

$\mathrm{H} 9 \mathrm{c} 2$ cells were harvested and $10^{5}$ cells were incubated with $10 \mu \mathrm{mol} / \mathrm{L} \mathrm{DCFH}-\mathrm{DA}$ at $37^{\circ} \mathrm{C}$ for $20 \mathrm{~min}$. The DCF fluorescence was detected by BD FACSCalibur excited at $488 \mathrm{~nm}$ and the emitted fluorescence was collected at $525 \mathrm{~nm}$.

\section{Determination of mitochondrial membrane potential $(\Delta \Psi \mathrm{m})$} $\mathrm{H} 9 \mathrm{c} 2$ cells were harvested and $10^{5}$ cells were loaded with JC-1 $(2 \mu \mathrm{M})$ at $37^{\circ} \mathrm{C}, 5 \% \mathrm{CO}_{2}$ for $20 \mathrm{~min}$, then analyzed by BD FACSCalibur excited at $488 \mathrm{~nm}$ and the emitted fluorescence was collected at $530 \mathrm{~nm}$ and $590 \mathrm{~nm}$. $\Delta \Psi \mathrm{m}$ was expressed as the emitted fluorescence ratio $(590 / 530 \mathrm{~nm})$ in percentage to the initial level, whereas $0 \%$ level was recorded after complete mitochondrial depolarization with carbonyl cyanide-p-trifluoromethoxyphenylhydra-zone.

\section{Langendorff heart perfusion}

Male Sprague-Dawley rats (weight 220 to $250 \mathrm{~g}$ ) were obtained from Jiangxi University of Traditional Chinese Medicine (China). All animals were treated in accordance with the Guide for the Care and Use of Laboratory Animals, and approved by the Ethics Committee of the first affiliated hospital of Nanchang University (permit No: NDYFY-2012-YYLSD-016). The rats were anesthetized with pentobarbital sodium $(100 \mathrm{mg} / \mathrm{kg}$ intraperitoneally). Hearts were excised and retrograde perfused via the aorta with modified Krebs-Henseleit buffer ( $\mathrm{NaCl} 118 \mathrm{nM}, \mathrm{KCl} 4.7 \mathrm{nM}, \mathrm{MgSO}_{4} 1.2 \mathrm{nM}, \mathrm{CaCl}_{2} 2.5 \mathrm{nM}$, $\mathrm{NaHCO}_{3} 2 \mathrm{nM}, \mathrm{KH}_{2} \mathrm{PO}_{4} 1.2 \mathrm{nM}$, Glucose $11 \mathrm{nM}, \mathrm{pH}$ 7.35-7.45) equilibrated with 95\% $\mathrm{O}_{2}-5 \% \quad \mathrm{CO}_{2}$. Left ventriculardeveloped pressure (LVDP), heart rate (HR) and intraventricular pressure $( \pm \mathrm{dP} / \mathrm{dt})$ were measured by Powerlab pressure transducer with a balloon inserted into the left ventricle. In the Control, Mock1 and Mock2 groups, hearts were buffer perfused without ischemia. In ischemia/reperfusion (I/R) group, hearts were first equilibrated for $20 \mathrm{~min}$ followed by $30 \mathrm{~min}$ of stop-flow ischemia and $120 \mathrm{~min}$ of reperfusion. In IPC group, after 3 cycles of $5 \mathrm{~min}$ of ischemia and $5 \mathrm{~min}$ of reperfusion, hearts were subjected to $30 \mathrm{~min}$ of no-flow ischemia, followed by $120 \mathrm{~min}$ of reperfusion. In IPost group, hearts were subjected to $30 \mathrm{~min}$ of stop-flow ischemia, before $120 \mathrm{~min}$ of reperfusion, 3 cycles of $10 \mathrm{~s}$ of ischemia and $10 \mathrm{~s}$ of reperfusion were applied.

\section{Lactate dehydrogenase (LDH) assay}

Coronary effluent was collected at 1 min before ischemia, $1 \mathrm{~min}$ after ischemia and $1 \mathrm{~min}$ after reperfusion to determine LDH activity by using LDH kits according to the manufacturer's instructions. LDH activity was expressed as international units per liter (IU/L).

\section{Assessment of infarct size}

The heart was frozen at $-20^{\circ} \mathrm{C}$ for $30 \mathrm{~min}$, then sectioned from apex to base into five to six $1 \mathrm{~mm}$ sections. The sections were incubated in $1 \% \mathrm{TTC}$ at $37^{\circ} \mathrm{C}$ for $30 \mathrm{~min}$ and fixed in $10 \%$ formaldehyde for $24 \mathrm{~h}$. The normal myocardium was stained brick red with TTC while the infarcted portion was not stained and appeared pale white. The infarct area-IA (white) and the area at risk-AAR (red and white) from each section were measured using Image Pro 6.0 Plus software. For each section, infarct size was expressed as the percentage of IA/AAR.

\section{Western blot analysis}

At different time points of the experiemtns, cells or the hearts were harvested immediately and lysed in cell lysis buffer (Beyotime Institute of Biotechnology, China) at $4^{\circ} \mathrm{C}$. Protein samples were separated by $8-10 \%$ SDS-PAGE, then transferred to nitrocellulose membranes (Millipore) and blocked in 10\% nonfat milk in TBST $(150 \mathrm{mM} \mathrm{NaCl}$, $50 \mathrm{mM}$ Tris pH 7.5, 0.1\% Tween-20). Membranes were incubated with primary antibodies overnight at $4^{\circ} \mathrm{C}$, followed by incubation with secondary antibodies at room temperature for $1 \mathrm{~h}$. The fluorescent signals were detected using enhanced chemiluminescence by ImageQuant LAS4000 (GE, USA). Relative protein levels were normalized to that of $\beta$-actin.

\section{Statistical analysis}

Data were analyzed using the SPSS version 12 statistical analysis package (SPSS Inc., Chicago, IL, USA). Examined data were assessed using ANOVA. In each test, the data were expressed as the mean $\pm \mathrm{SD}$, and $\mathrm{P}<0.05$ was accepted as statistically significant.

\section{Results}

Identification of LV-N1ICD and LV-N1ICD-shRNA vectors In $293 \mathrm{~T}$ cells transfected with pGC-FU-N1ICD-3Flag vector, we observed ectopic expression of N1ICD (Figure 1A). Furthermore, in $\mathrm{H} 9 \mathrm{c} 2$ cells and rats infected with lentiviral vector LV-N1ICD, we observed ectopic expression of N1ICD in the cells or hearts (Figure 1B-C). In contrast, in $293 \mathrm{~T}$ cells cotransfected with pGC-FUN1ICD-3Flag vector and N1ICD-shRNA-1 to 4, we 


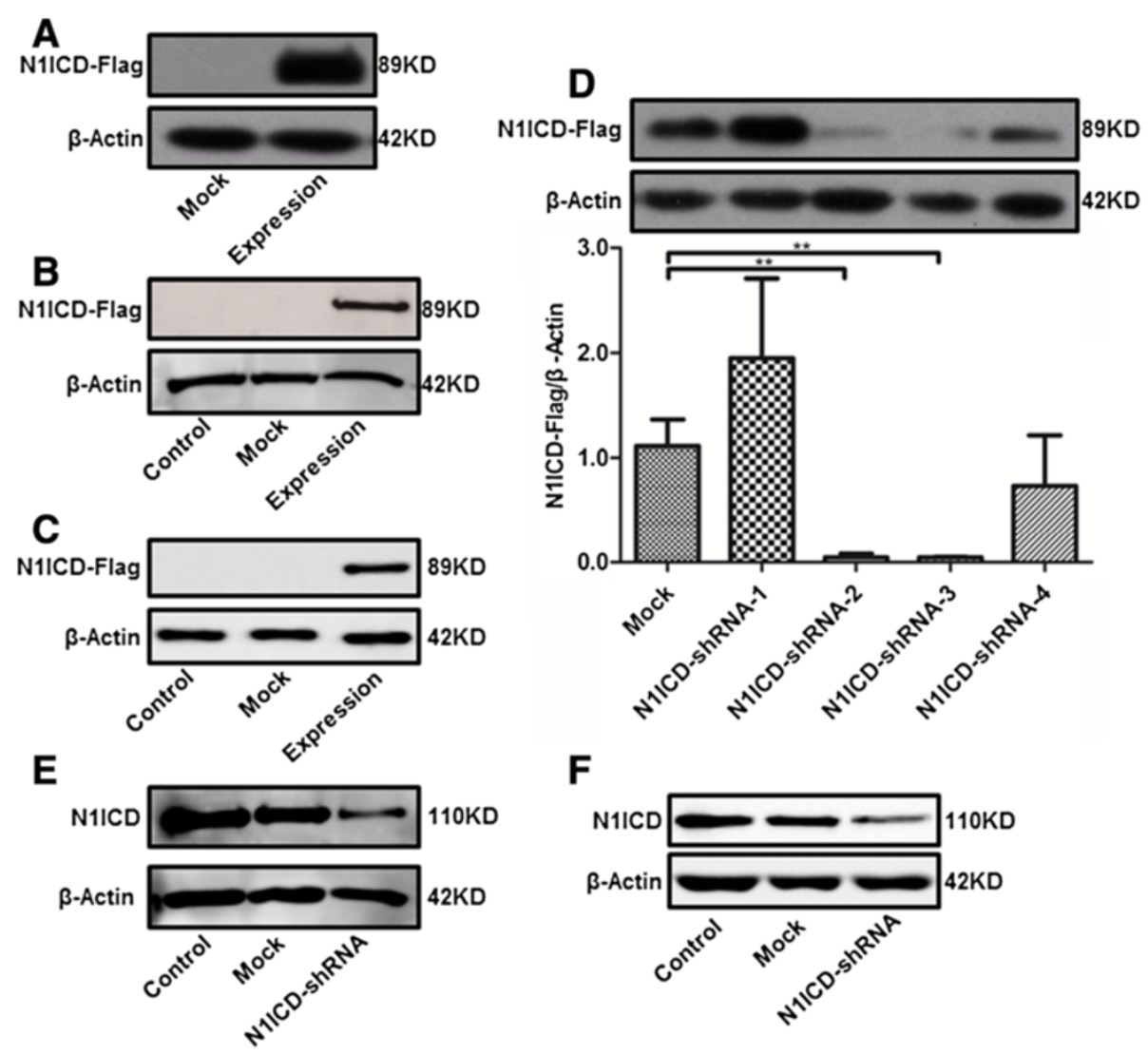

Figure 1 Identification of LV-N1ICD and LV-N1ICD-shRNA vectors. A, Western blots showing the expression of Flag tagged N1ICD in 293T cells as indicated. B, Western blots showing the expression of Flag tagged N1ICD in H9c2 cells as indicated. C, Western blots showing the expression of Flag tagged N1ICD in the hearts of the rats as indicated, D, Western blots showing the expression of Flag tagged N1ICD in 293T cells transfected with pGC-FU-N1ICD-3Flag along with negative control pGVC112-shRNA (Mock), pGVC112-N1ICD-shRNA-1 (N1ICD-shRNA-1), pGVC112-N1ICD-shRNA-2 (N1ICD-shRNA-2), pGVC112-N1ICD-shRNA-3 (N1ICD-shRNA-3), or pGVC112-N1ICD-shRNA-4 (N1ICD-shRNA-4). E, Western blots showing the expression of endogenous N1ICD in H9c2 cells infected by lentivirus as indicated, $\mathbf{F}$, Western blots showing the expression of endogenous N1ICD in the hearts of the rats infected by lentivirus as indicated. $\beta$-actin was loading control.

observed significant knockdown of N1ICD expression in cells transfected with N1ICD-shRNA-3 (Figure 1D). Thus we constructed N1ICD lentiviral interference vector (LV-N1ICD-shRNA) using the sequence of N1ICDshRNA-3 and infected $\mathrm{H} 9 \mathrm{c} 2$ cells or rats, we observed efficient knockdown of endogenous N1ICD expression in the cells or hearts (Figure 1E-F). Taken together, these results suggest that LV-N1ICD and LV-N1ICD-shRNA vectors are efficient to overexpress and knockdown N1ICD in vitro and in vivo, respectively.

Notch1 signaling is activated during myocardial IPC and IPost Western blot analysis showed that N1ICD and Hes1 expression in $\mathrm{H} 9 \mathrm{c} 2$ cells was increased slightly during $\mathrm{H} / \mathrm{R}$ but increased significantly during IPC and IPost (Figure 2A and $2 \mathrm{~B}$ ). In addition, Hes1 level was increased in $\mathrm{H} 9 \mathrm{c} 2$ cells treated by LV-N1ICD infection and H/R, but decreased in $\mathrm{H} 9 \mathrm{c} 2$ cells treated by LV-N1ICD-shRNA infection and IPC or IPost (Figure 2B), confirming that Hes1 is a target gene of Notch signaling. These data suggest that Notch1 signaling is activated during myocardial IPC and IPost.

Myocardial IRI is mitigated by activated Notch1 signaling To investigate the role of Notch1 signaling in myocardial protection, the cell viability was detected after $\mathrm{H} 9 \mathrm{c} 2$ cells were exposed to H/R, IPC or IPost. Ectopic expression of N1ICD in H9c2 cells exposed to H/R enhanced myocardial cell viability, however, the viability of myocardial cells exposed to IPC and IPost was decreased when N1ICD was knockdown by LV-N1ICD-shRNA (Figure 3A).

Next, we observed the effect of Notch1 signaling on cell apoptosis after myocardial ischemia. The results demonstrated that the apoptosis of cardiomyocyte in $\mathrm{H} / \mathrm{R}$ was greatly reduced after N1ICD overexpression, but it was substantially increased upon N1ICD knockdown 

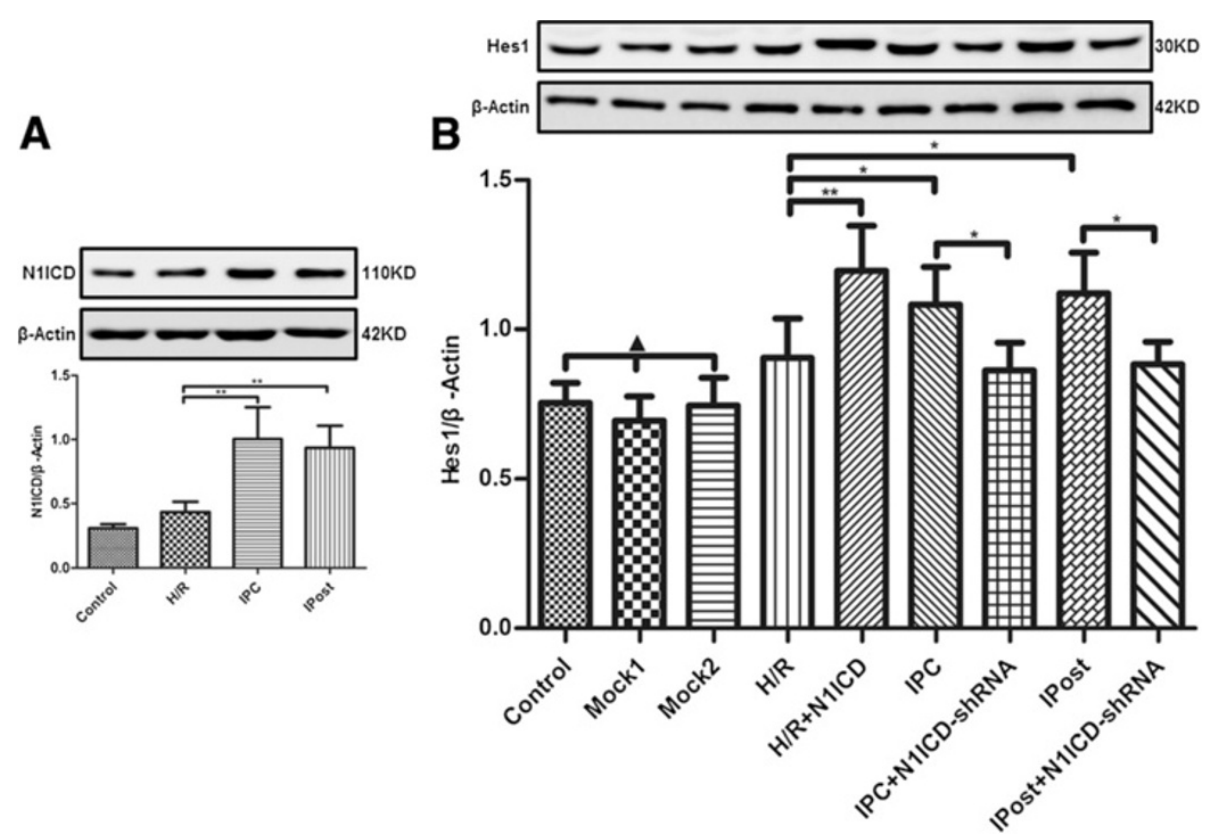

Figure 2 Notch1 signaling is activated in H9c2 cells exposed to IPC and IPost. A, N1ICD level was upregulated in IPC and IPost. B, Hes1 level was regulated by H/R, IPC and IPost with or without LV-N1ICD/LV-N1ICD-shRNA infection. Data were presented as mean $\pm S D, n=3$. Mock1 indicated cells infected with empty vector, Mock 2 indicated cells infected with vector containing nonspecfic sequences. $\mathbf{\Delta} P>0.05,{ }^{*} P<0.05,{ }^{*} P<0.01$.

during IPC and IPost (Figure 3B). Taken together, these data suggest that Notch1 signaling mitigates myocardial IRI by promoting the viability and inhibiting the apoptosis of cardiomyocytes.

Notch 1 signaling inhibits the mitochondrial permeability transition pore (mPTP) opening in cardiomyocytes

To observe the effect of Notch1 on mPTP during IRI, we detected $\Delta \Psi \mathrm{m}$ by JC-1 staining. We observed that LV-N1ICD infection during $H / R$ prevented mitochondrial from serious depolarization, while LV-N1ICD-shRNA infection during IPC and IPost exerted opposite effect, $\Delta \Psi \mathrm{m}$ became extremely low that showed no significant difference compared with H/R (Figure 4A). These data indicate that activated Notch1 suppresses the opening of MPTP.

Next we measured intracellular ROS in H9c2 cells and found that ectopic expression of N1ICD mitigated ROS accumulation caused by $H / R$, but knockdown of N1ICD promoted ROS accumulation during IPC and IPost (Figure 4B). These data suggest that Notch1 signaling inhibits mPTP opening in cardiomyocytes via the reduction of intracellular ROS accumulation.

Notch1 signaling activates Stat3 and regulates apoptosis related proteins in cardiomyocytes

To explore the molecular mechanism underlying Notch1 mediated cardioprotection, we detected Stat3 phosphorylation in $\mathrm{H} 9 \mathrm{c} 2$ cells. The phosphorylation of Stat3 was elevated not only upon IPC or IPC treatment, but also in N1ICD overexpressed H9c2 cells under H/R. However, the elevated phosphorylation of Stat3 was immediately reversed upon N1ICD knockdown during IPC or IPost (Figure 5A).

Furthermore, we detected anti-apoptosis protein Bcl-xl and pro-apoptosis protein Bax in H9c2 cells. The results showed that ectopic expression of N1ICD increased Bcl-xl expression and decreased Bax expression under $\mathrm{H} / \mathrm{R}$, but N1ICD knockdown during IPC or IPost decreased Bcl-xl level and increased Bax level (Figure 5B). Collectively, these data provide evidence that cardioprotection effects of Notch 1 signaling are mediated by Stat 3 activation and regulation of apoptosis related proteins.

Notch1 signaling contributes to the restoration of cardiac function in post-ischemia rats

After langendorff-perfused isolated heart models were established, we measured the parameters of cardiac function. The results showed that the recovery of cardiac function in $\mathrm{I} / \mathrm{R}$ was strengthened by ectopic expression of N1ICD, as evidenced by the increases of HR, LVDP and $\pm \mathrm{dp} / \mathrm{dt}$. However, upon N1ICD knockdown, the recovery effects of IPC or IPost on cardiac function disappeared because the values of HR, LVDP and $\pm d p / d t$ were decreased to basic level of I/R (Figure 6). In addition, we found that N1ICD and Hes1 expression in myocardium 


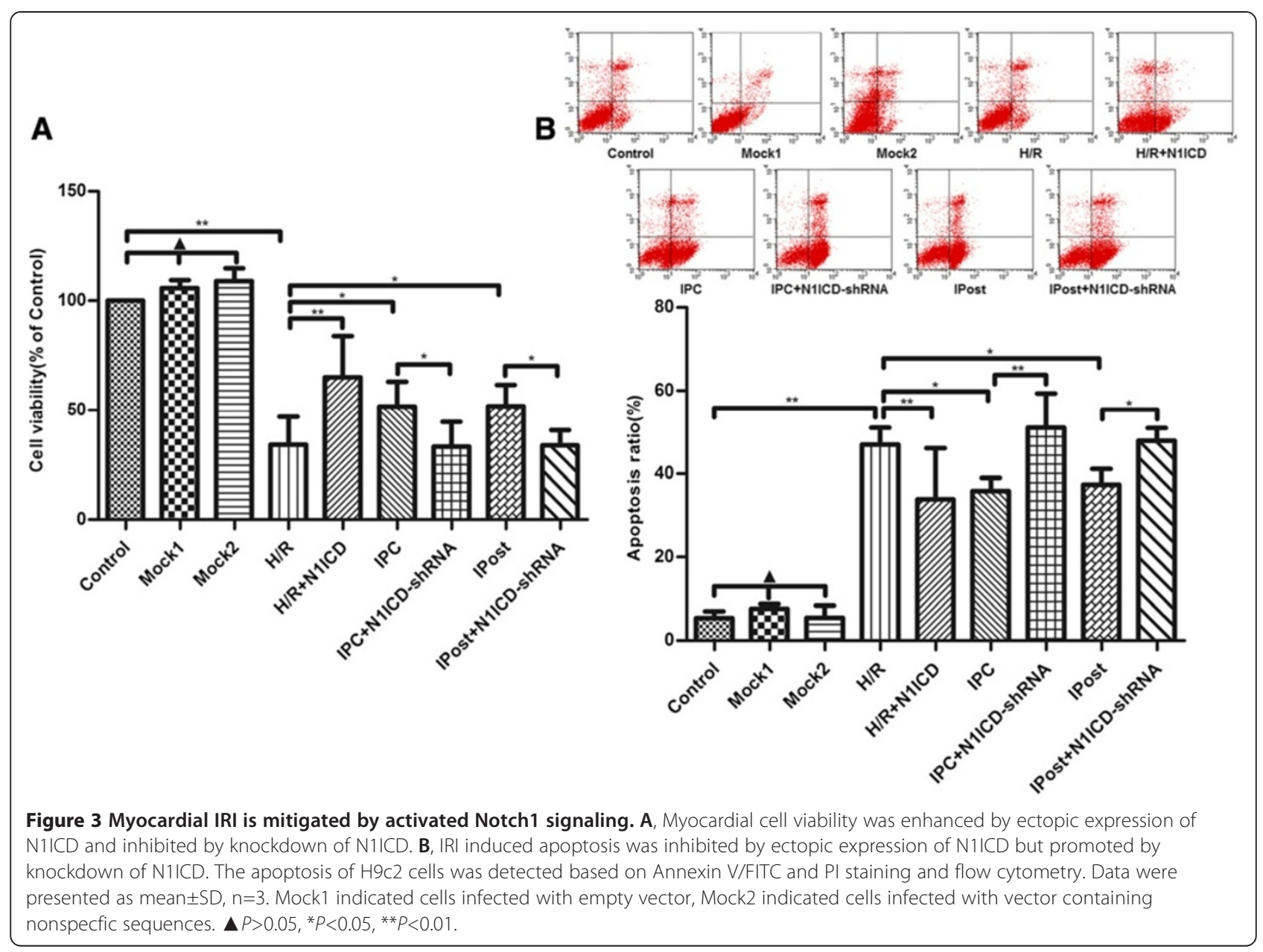

was higher in IPC and Ipost, and Hes1 level was affected by LV-N1ICD or LV-N1ICD-shRNA (Figure 7A and 7B). These data suggest that Notch1 signaling is activated during IPC and IPost in langendorff-perfused isolated heart models, and Notch1 signaling contributes to the restoration of cardiac function after ischemia.

\section{Notch1 signaling reduces myocardial necrosis after ischemia in rats}

Global ischemia for $30 \mathrm{~min}$ followed by $120 \mathrm{~min}$ of reperfusion markedly increased the release of LDH. Three episodes of IPC and IPost significantly reduced I/R induced increase in the release of LDH. Moreover, IPC caused decrease in the release of LDH was significantly restored in LV-N1ICD-shRNA infected rat hearts. However, ectopic expression of N1ICD significantly attenuated the increase in the release of LDH (Figure 8A). Similarly, the increased infarct size induced by $\mathrm{I} / \mathrm{R}$ was limited by ectopic expression of N1ICD and by IPC or IPost treatment. However, N1ICD knockdown led to significant increase in infarct size during IPC and IPost (Figure 8B and 8C). These data indicate that Notch1 signaling can reduce myocardial necrosis after ischemia. Furthermore, the phosphorylation of Stat3 was enhanced by IPC and IPost treatment, or by N1ICD overexpressed in I/R. However, the elevated phosphorylation of Stat3 was obviously decreased upon N1ICD knockdown during IPC or IPost (Figure 7C).

\section{Discussion}

The activation of Notch signaling following tissue injury has been documented in various tissues $[14,15]$. In this study we observed that the expression of N1ICD and Hes1 was greatly increased in H9c2 cells exposed to IPC and IPost, but not to $H / R$, suggesting that endogenous cardioprotection phenomenon is associated with the activation of Notch signaling. These data are consistent with recent findings that Notch1 signaling is implicated in myocardial protection mediated by IPC [16]. In addition, we found that IR-induced necrosis and apoptosis in H9c2 cardiomyocytes were mitigated by activated Notch1 signaling. Furthermore, in langendorff isolated heart perfusion model, we demonstrated that activation of Notch1 not only reduced the release of LDH and limited the infarct size, but also improved cardiac function after ischemia. 


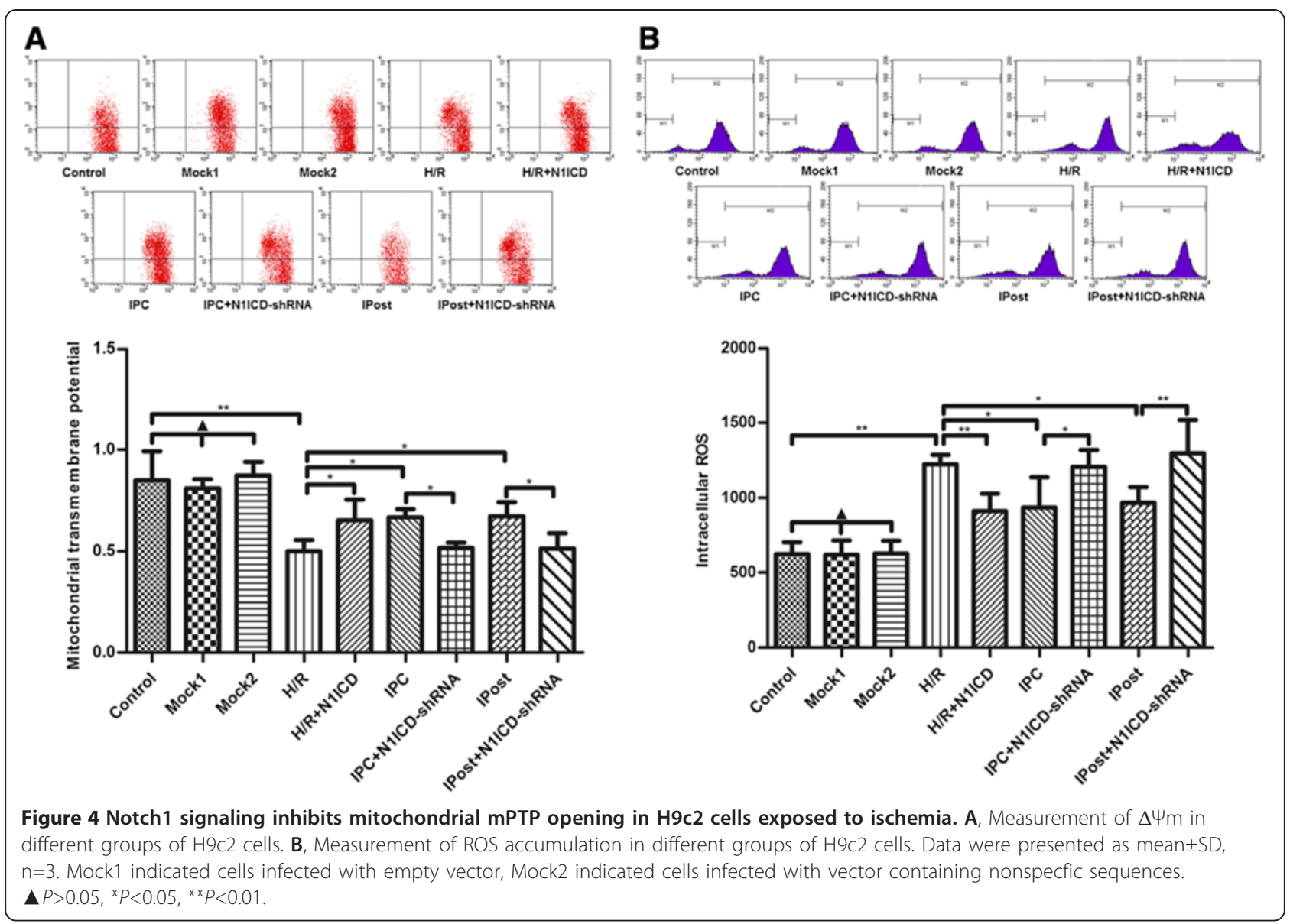

Collectively, these data suggest that Notch1 acts as an endogenous cardioprotcetive factor to play an important role in the protection of ischemic myocardium during IPC and IPost.

mPTP is a non-specific channel in the mitochondrial inner membrane. Experimental evidences suggest that irreversible opening of $\mathrm{MPTP}$ is a critical mediator of lethal IRI, but IPC and IPost can direct or indirectly inhibit the opening of MPTP by various survival signaling pathway [17]. In the present study, we monitored the mPTP opening by $\Delta \Psi \mathrm{m}$ and found that activated Notch1 alleviated the loss of $\Delta \Psi \mathrm{m}$ induced by $\mathrm{H} / \mathrm{R}$, while knockdown of N1ICD during IPC and IPost exacerbated the loss of $\Delta \Psi \mathrm{m}$. These results indicate that the MPTP opening induced by $\mathrm{H} / \mathrm{R}$ is partly inhibited by Notch1 signaling. Furthermore, we found that Notch1 decreased the production of intracellular ROS during $H / R$, in agreement with previous results that Notch1 signaling protected hepatocytes from IRI by repressing ROS [18].

Cardiomyocyte apoptosis is a complex molecular event controlled by a variety of apoptosis related proteins such as Bcl-2 family. The Bcl-2 family consists of pro-apoptotic factors such as Bad, Bid and Bax, and anti-apoptotic factors such as Bcl-2 and Bcl-xl. Bax can directly induce mPTP opening, leading to the release of cytochrome $\mathrm{C}$ and the activation of apoptotic signaling pathways [19]. Notch signaling could upregulate $\mathrm{Bcl}-2$ and $\mathrm{Bcl}-\mathrm{xl}$ expression and downregulate Bax and Bim expression, thereby inhibiting apoptosis [20]. In current study, the upregulation of Bax and downregulation of Bcl-xl induced by $H / R$ were reversed by activated Notch 1 signaling, but were promoted upon knockdown of N1ICD during IPC and IPost. Therefore, we propose that Notch1 inhibits myocardial apoptosis induced by IRI through regulating the expression of Bcl-2 family members.

Several studies have shown that the activation of Stat3 in IR not only reduces cardiomyocyte death, but also attenuates adverse cardiac remodeling [21,22]. Furthermore, myocardial IPC and IPost can enhance Stat3 phosphorylation and activity, which contribute to the cardioprotection provided by IPC and IPost [23,24]. In the current study, Stat3 phosphorylation was upregulated during endogenous cardioprotection mediated by IPC and IPost, but was inhibited upon the knockdown of N1ICD. 

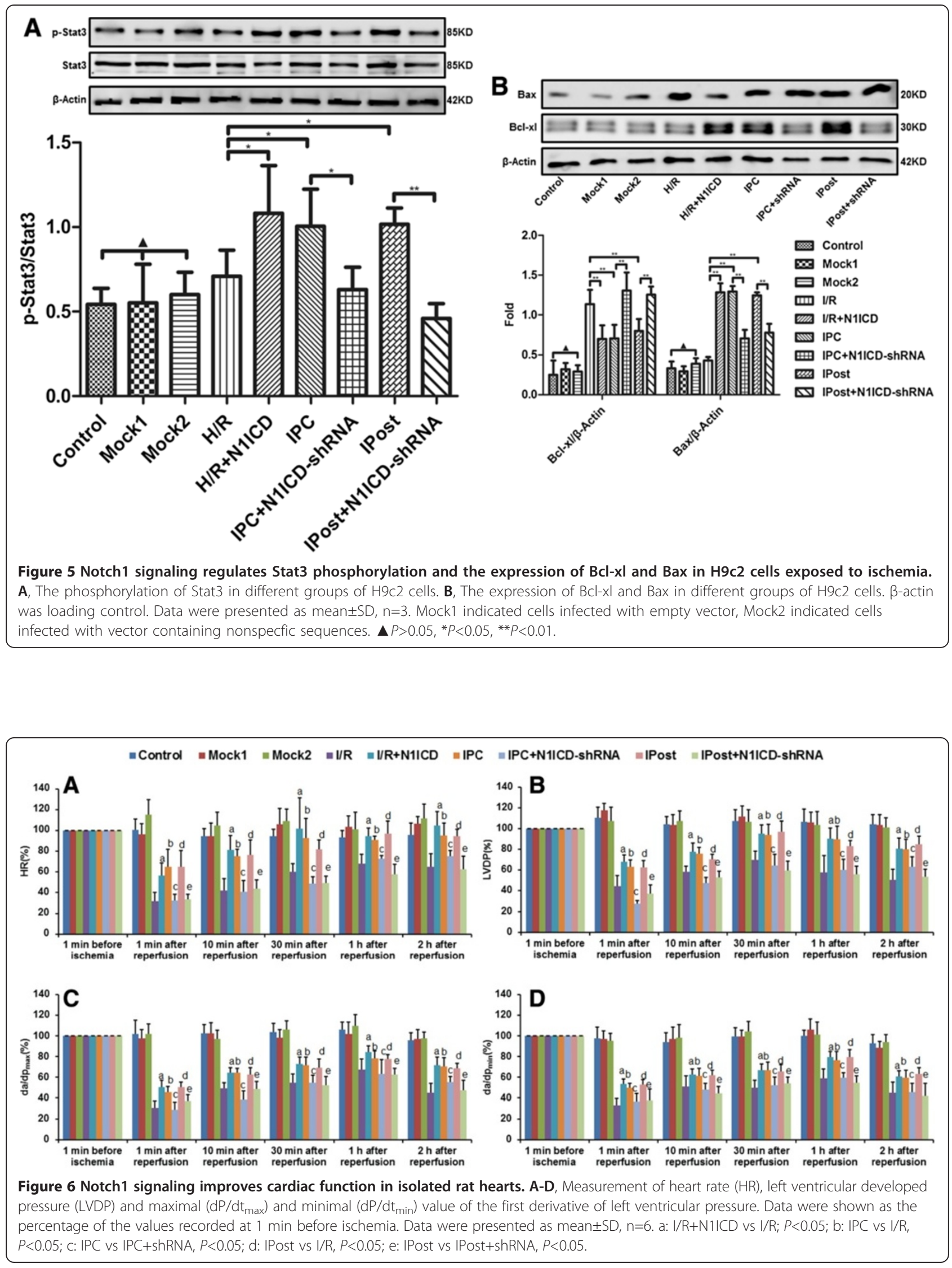


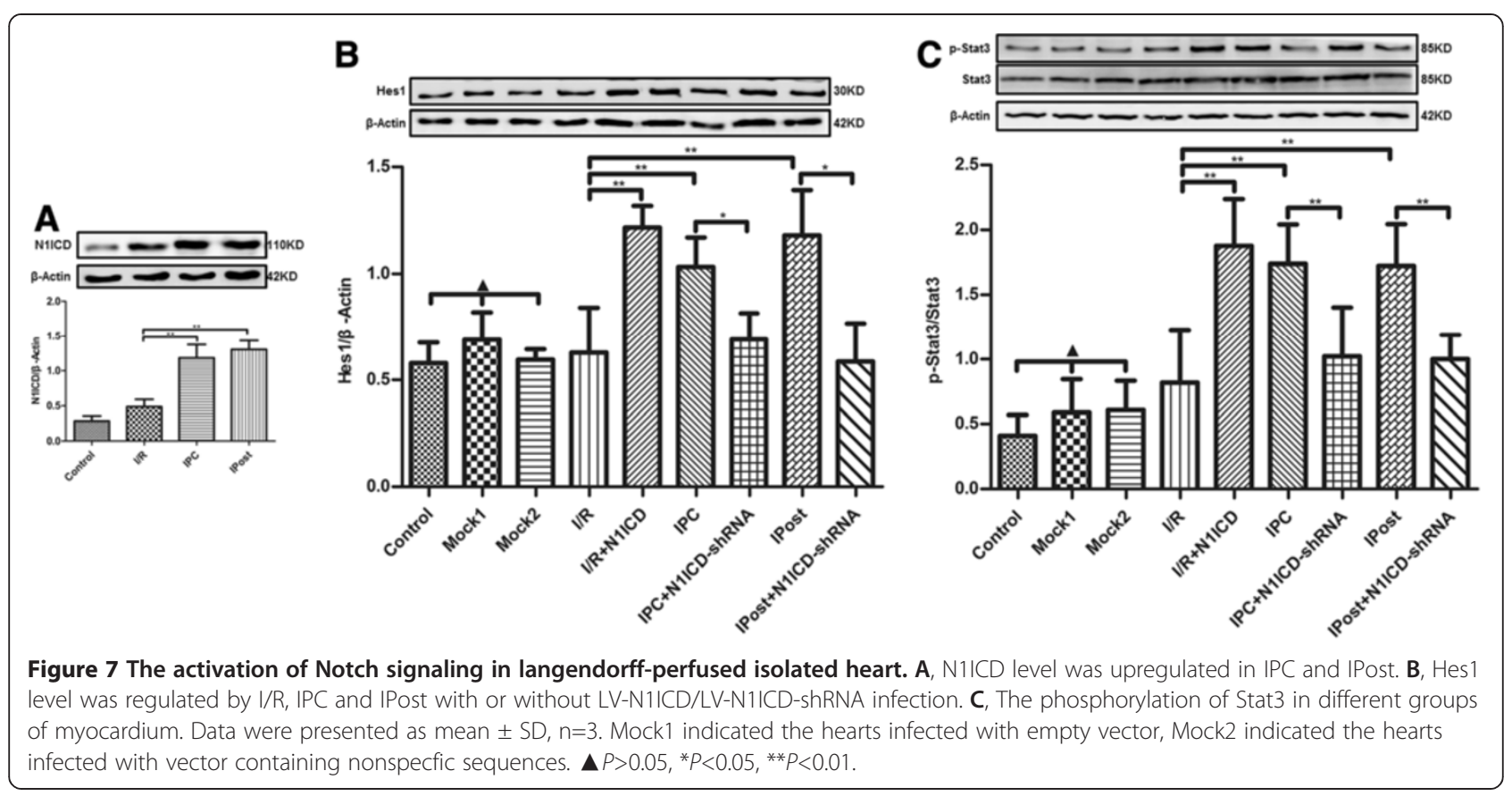

These data suggest that Notch1 signaling prevents myocardium from IRI by enhancing Stat3 phosphorylation and activation.

\section{Conclusions}

In summary, in this study we provide a series of evidence that Notch1 signaling is activated and mediates cardioprotection provided by IPC and IPost. Notch1 signaling exerts endogenous cardioprotection to mitigate IRI through the inhibition of $\mathrm{mPTP}$ opening, the regulation of Bcl-2 family member expression, and the activation of Stat3. Our results suggest that Notch1 signaling may represent a potential new pharmacologic mimic for cardioprotection of IHD.

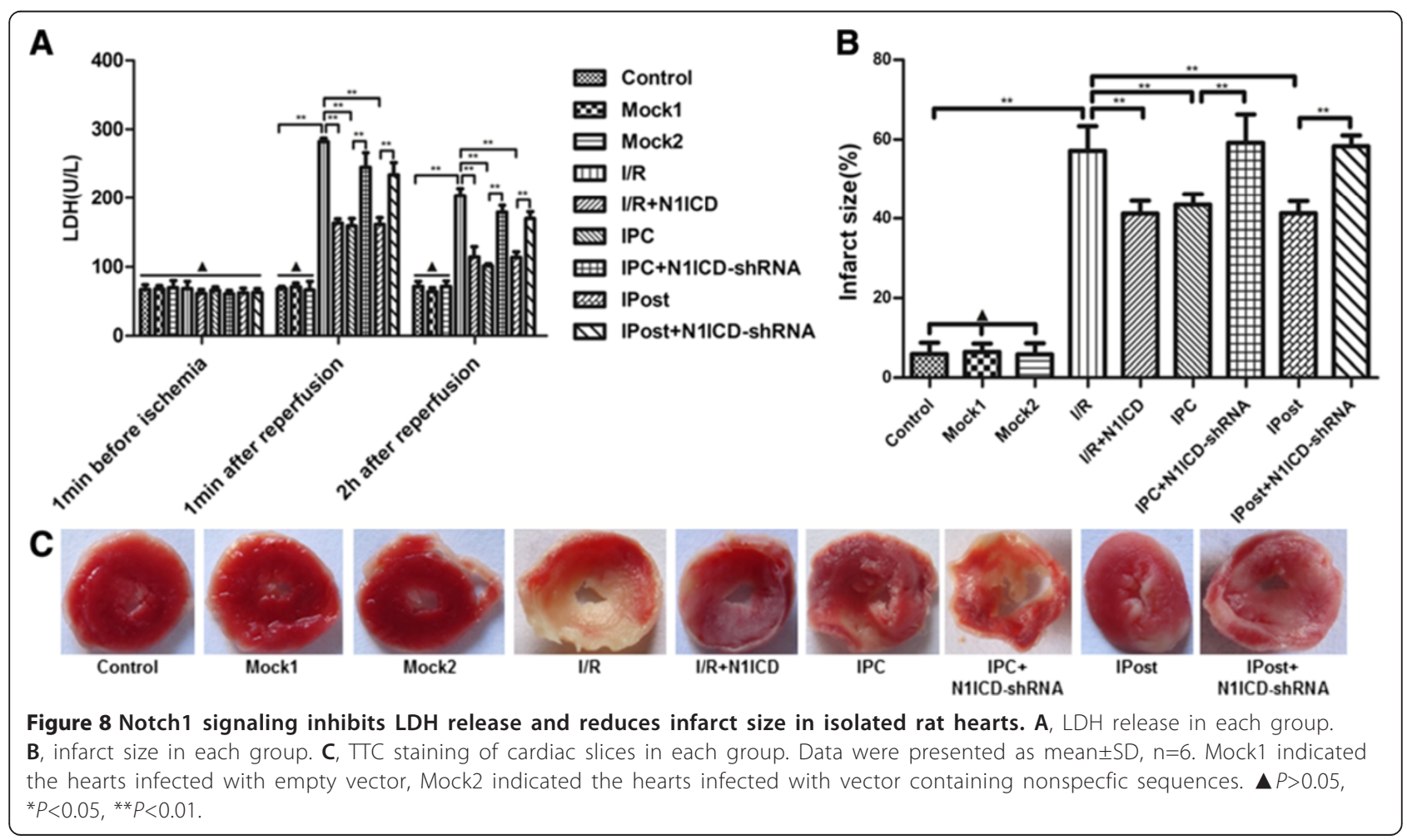




\section{Competing interests}

The authors declare that they have no competing interests.

\section{Authors' contributions}

Conceived and designed the experiments: J-CL. Performed the experiments: $X-I Z, L W, Q-r X$. Analyzed the data: YZ. Wrote the paper: $X-I Z$ and J-CL. All authors read and approved the final manuscript.

\section{Acknowledgments}

This work was supported in part by grants from the National Natural Science Foundation of China (No: 81260024), the Natural Science Foundation of Jiangxi Province (No: 20122BAB205026, No: 20132BAB205033).

Received: 19 August 2013 Accepted: 30 September 2013 Published: 8 October 2013

\section{References}

1. Minamino T: Cardioprotection from ischemia/reperfusion injury: basic and translational research. Circ J 2012, 76:1074-1082.

2. Gerczuk PZ, Kloner RA: An update on cardioprotection: a review of the latest adjunctive therapies to limit myocardial infarction size in clinical trials. J Am Coll Cardiol 2012, 59:969-978.

3. Apostolakis E, Baikoussis NG, Papakonstantinou NA: The role of myocardial ischaemic preconditioning during beating heart surgery: biological aspect and clinical outcome. Interact Cardiovasc Thorac Surg 2012, 14:68-71.

4. Zhao ZQ, Corvera JS, Halkos ME, Kerendi F, Wang NP, Guyton RA, Vinten-Johansen J: Inhibition of myocardial injury by ischemic postconditioning during reperfusion: comparison with ischemic preconditioning. Am J Physiol Heart Circ Physiol 2003, 285:H579-588.

5. Huang C, Yitzhaki S, Perry CN, Liu W, Giricz Z, Mentzer RM Jr, Gottlieb RA: Autophagy induced by ischemic preconditioning is essential for cardioprotection. J Cardiovasc Transl Res 2010, 3:365-373.

6. Babiker FA, van Golde J, Vanagt WY, Prinzen FW: Pacing postconditioning: impact of pacing algorithm, gender, and diabetes on its myocardial protective effects. J Cardiovasc Transl Res 2012, 5:727-734.

7. Schwanbeck R, Martini S, Bernoth K, Just U: The notch signaling pathway: molecular basis of cell context dependency. Eur J Cell Biol 2011, 90:572-581.

8. Kopan R: Notch signaling. Cold Spring Harb Perspect Biol 2012, 4:10. doi:10.1101/cshperspect.a011213.

9. Gude NA, Emmanuel G, Wu W, Cottage CT, Fischer K, Quijada P, Muraski JA, Alvarez R, Rubio M, Schaefer E, Sussman MA: Activation of notch-mediated protective signaling in the myocardium. Circ Res 2008, 102:1025-1035.

10. Kratsios P, Catela C, Salimova E, Huth M, Berno V, Rosenthal N, Mourkioti F: Distinct roles for cell-autonomous notch signaling in cardiomyocytes of the embryonic and adult heart. Circ Res 2010, 106:559-572.

11. Croquelois A, Domenighetti AA, Nemir M, Lepore M, Rosenblatt-Velin N, Radtke F, Pedrazzini T: Control of the adaptive response of the heart to stress via the notch1 receptor pathway. J Exp Med 2008, 205:3173-3185.

12. Collesi C, Zentilin L, Sinagra G, Giacca M: Notch1 signaling stimulates proliferation of immature cardiomyocytes. J Cell Bio/ 2008, 183:117-128.

13. Campa VM, Gutierrez-Lanza R, Cerignoli F, Diaz-Trelles R, Nelson B, Tsuji T, Barcova M, Jiang W, Mercola M: Notch activates cell cycle reentry and progression in quiescent cardiomyocytes. J Cell Biol 2008, 183:129-141.

14. Lovschall H, Tummers M, Thesleff I, Fuchtbauer EM, Poulsen K: Activation of the notch signaling pathway in response to pulp capping of rat molars. Eur J Oral Sci 2005, 113:312-317.

15. Givogri MI, de Planell M, Galbiati F, Superchi D, Gritti A, Vescovi A, de Vellis J, Bongarzone ER: Notch signaling in astrocytes and neuroblasts of the adult subventricular zone in health and after cortical injury. Dev Neurosci 2006, 28:81-91.

16. Yang Y, Duan W, Jin Z, Bi S, Yan J, Jin Y, Lu J, Yang J, Yi D: New role of notch-mediated signaling pathway in myocardial ischemic preconditioning. Med Hypotheses 2011, 76:427-428.

17. Hausenloy DJ, Ong SB, Yellon DM: The mitochondrial permeability transition pore as a target for preconditioning and postconditioning. Basic Res Cardiol 2009, 104:189-202.

18. Yu HC, Qin HY, He F, Wang L, Fu W, Liu D, Guo FC, Liang L, Dou KF, Han H: Canonical notch pathway protects hepatocytes from ischemia/reperfusion injury in mice by repressing reactive oxygen species production through jak2/stat3 signaling. Hepatology 2011, 54:979-98826.
19. Kinnally KW, Antonsson B: A tale of two mitochondrial channels, mac and ptp, in apoptosis. Apoptosis 2007, 12:857-868.

20. Gao F, Yao M, Shi Y, Hao J, Ren Y, Liu Q, Wang X, Duan H: Notch pathway is involved in high glucose-induced apoptosis in podocytes via bcl-2 and p53 pathways. J Cell Biochem 2013, 114:1029-1038.

21. Boengler K, Buechert A, Heinen Y, Roeskes C, Hilfiker-Kleiner D, Heusch G, Schulz R: Cardioprotection by ischemic postconditioning is lost in aged and stat3-deficient mice. Circ Res 2008, 102:131-135.

22. Obana M, Maeda M, Takeda K, Hayama A, Mohri T, Yamashita T, Nakaoka Y, Komuro I, Matsumiya G, Azuma J, Fujio Y: Therapeutic activation of signal transducer and activator of transcription 3 by interleukin- 11 ameliorates cardiac fibrosis after myocardial infarction. Circulation 2010, 121:684-691.

23. You L, Li L, Xu Q, Ren J, Zhang F: Postconditioning reduces infarct size and cardiac myocyte apoptosis via the opioid receptor and jak-stat signaling pathway. Mol Biol Rep 2011, 38:437-443.

24. Hausenloy DJ, Lecour S, Yellon DM: Reperfusion injury salvage kinase and survivor activating factor enhancement prosurvival signaling pathways in ischemic postconditioning: Two sides of the same coin. Antioxid Redox Signal 2011, 14:893-907.

doi:10.1186/1479-5876-11-251

Cite this article as: Zhou et al:: Notch signaling activation contributes to cardioprotection provided by ischemic preconditioning and postconditioning. Journal of Translational Medicine 2013 11:251.

\section{Submit your next manuscript to BioMed Central and take full advantage of:}

- Convenient online submission

- Thorough peer review

- No space constraints or color figure charges

- Immediate publication on acceptance

- Inclusion in PubMed, CAS, Scopus and Google Scholar

- Research which is freely available for redistribution

Submit your manuscript at www.biomedcentral.com/submit
C Biomed Central 